\title{
EXPERIMENTAL EVALUATION OF STATIC AND FATIGUE STRENGTH OF ALUMINIUM-BASED STRUCTURAL METALLIC ALLOYS
}

\author{
Margarita Urbaha $^{1}$, Vladislavs Turko ${ }^{1}$, Ivans Agafonovs ${ }^{1}$, Aleksandrs Sorokins $^{2}$ \\ ${ }^{1}$ Riga Technical University, Latvia; ${ }^{2 " A v i a t e s t " ~ L T D, ~ L a t v i a ~}$ \\ urbaha.margarita@gmail.com, vladislav.turko@gmail.com, ivans.agafonovs@rtu.lv, \\ aleksandrs.sorokins@aviatest.lv
}

\begin{abstract}
The paper presents the results of the research for the static and fatigue strength of specimens made of aluminum-based high-strength alloys B95 and 1163. Specimens of different thickness sized $220 \mathrm{~mm}$ x $36 \mathrm{~mm}$ with a hole in the middle with a diameter of $6 \mathrm{~mm}$ have been loaded by using INSTRON 8801 and 8802 testing machines. The total sample volume worked out 400 specimens. The fatigue tests were carried out at cyclic regular loading with a frequency of $5 \mathrm{~Hz}$. For the estimation of the effect of single-shot tensile and compressive static peak loads have been applied in blocks. S-N fatigue curves for various configurations of loading blocks have been plotted based on the results of the fatigue tests, the influence of various loading blocks on fatigue life have been compared for samples of two aluminum alloys.
\end{abstract}

Keywords: aluminum alloys, fatigue durability, fatigue block test.

\section{Introduction}

The evaluation of the fatigue strength of materials by conducting static and fatigue tests of specimens is one of the most important stages during the operational refinement of materials and designs

The need to solve this problem arouses during the development of engineering structures. At that point the life time has been defined as a Service Life Limit (SLL). But different load conditions [1], complication of Designs, increasing its size and variety of impacts on them (the environment and loads) leads to the difficulties of experimental verification of its reliability and durability. By this the duration of testing of full-sized structures lead to the expansion of comparative studies of various materials, sizes and loading conditions of Designs. So again, it was necessary to conduct comparative experiments and fatigue tests of structurally similar samples, structural significant items (SSI) and materials under different loading conditions $[2 ; 3]$.

Refusal of the principle of fixed durability (SSL) leads to develop the non-destruction treatment systems, which provides the principle of design operation according to the technical condition, such as Structural Health Monitoring (SHM), Health Usage Monitoring (HUMS) and Fail Safe Design Concept (FSDC) . But such a development of systems is impossible without further experimental study and comparison of the summation of fatigue damages under various loading conditions [4].

In the present work, comparative tests of aluminum alloys B95(Fe-Si-Mn-Ni-Cr-Ti-AI-Cu-Mg$\mathrm{Zn})$ and $1163(\mathrm{AI}-\mathrm{Cu}-\mathrm{Mg}-\mathrm{Mn}-\mathrm{Ti}-\mathrm{Fe}-\mathrm{Si}-\mathrm{Zn}-\mathrm{Ni})$ specimens were carried out. As a result of static tests and fatigue tests, including block loading tests, fatigue resistance characteristics were obtained. It was investigated the fatigue life under the effect of tension and/or compression peak loads in various blocks loading.

The main goal of this research is to compare the influence of various single peak loads during block tests to the fatigue endurance of specimens. This peak loads simulate the shock impact or overloading of the design during a service life. So, the attempt has been made to quantify the risk of significant influence on the working ability under different load conditions.

The maximal value of single peak load composed the $80 \%$ of the ultimate tensile strength. For that the static test were performed for each of alloy sample.

This study did not take into account the difference in stress concentration [5], the stress gradient across the thickness [6], and other factors depending on the difference in the specimens thickness and affecting the magnitude of the fatigue characteristics.

\section{Materials and methods}

For the study, specimens were made of aluminum alloys B95 - the most durable and hard alloy, resistant to corrosion and alloy 1163 - medium-strength high-life alloy used for elements operating under condition, critical to fatigue tensile loads. Specimens have dimensions of $220 \mathrm{~mm}$ x $36 \mathrm{~mm}$ and 
a thickness of $5 \mathrm{~mm}$ for B95 and $1.5 \mathrm{~mm}$ for 1163. A hole with a diameter of $6 \mathrm{~mm}$ was drilled symmetrically in each specimen. 200 specimens of each alloy were manufactured and tested. The shape of the specimen ("strip with a hole") is shown on Fig. 1,a for 1163 alloy and Fig.1,b for B95 alloy . The Instron test machines have been using (Fig. 1, c). For loading under compressive load, to eliminate the possible loss of stability, specially made plates were used (Fig. 1, c). The loading error is not more than $1.5 \%$ of the load.

Initially, in order to estimate the limits of applied cyclic loads, two samples of specimens were tested on static load strength. To estimate the static ultimate tensile strength (breaking load), five B95alloy specimens and five 1163-alloy specimens were loaded to fracture. The results of these testing are presented in the Table 1 . These results have been used for the determination of main loads for regular cyclic loads and the single peak (both tension and compression) loads. Fatigue tests were conducted on 195 specimens of each material with the seven different loading plans (Table 2). At each position of the experiment's loading plan, samples of 15 specimens of each alloy were tested by five specimens at each of the three specified loading levels $\left(P_{\max }=0.5 ; 0.4\right.$ and 0.3 from $\left.P_{\max }\right)$ where $P_{\max }$ was determined from static tests as ultimate tension strength to failure. Cyclic loading frequency have been take on $5 \mathrm{~Hz}$.

a)

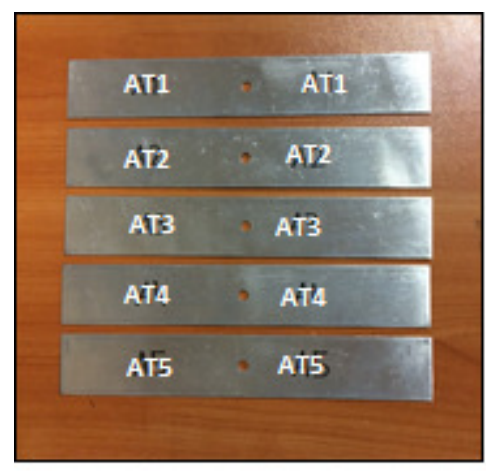

b)

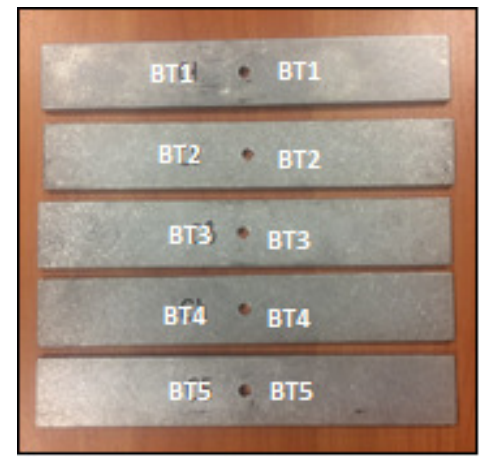

c)

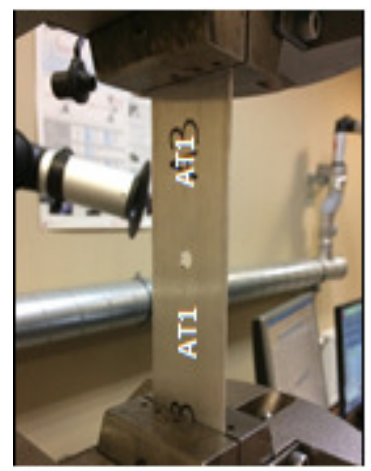

Fig.1 General view of specimens and test equipment: a - test specimens 1163;

$\mathrm{b}$ - test specimens B95; $\mathrm{c}$ - specimen in testing machine jaws

Table 1

Statistical characteristics of specimens' static ultimate tension strength

\begin{tabular}{|l|c|c|}
\hline \multicolumn{1}{|c|}{ Alloy } & B95 & $\mathbf{1 1 6 3}$ \\
\hline Average of failure load $P_{u l}, \mathrm{P}$ & 74985.6 & 16898.2 \\
\hline Root mean square deviation (standard deviation), $S, \mathrm{P}$ & 441.93 & 190.05 \\
\hline Coefficient of variation $V, \%$ & 0.5893 & 1.1247 \\
\hline Ultimate stress limit, Mpa & 513.48 & 416.00 \\
\hline Ultimate Stress Standard deviation, Mpa & 2.26188 & 3.2698 \\
\hline The coefficient of variation of ultimate stress limit, \% & 0.4404 & 0.7860 \\
\hline
\end{tabular}

The average (mean), root-mean-square deviation (standard deviation) and coefficient of variation are determinate and calculated as it is shown in [7].

As it can see, the obtained values of ultimate static strength of samples are in the ranges defined by regulatory documentation. These values are accepted as the basis for the definition of the range of strain for the cyclic loading.

It should be noted, that usually fatigue data treatment are carried out with the logarithm of shown values. The accepted value are presented in Table 2

Table 2

The accepted maximum loads (stress) of the pulsating regular cyclic loading

\begin{tabular}{|c|c|c|c|c|}
\hline \multirow{2}{*}{ Alloy } & Ultimate tension stress. & \multicolumn{3}{|c|}{ Logarithm of maximum cyclic tension stress (range) } \\
\cline { 3 - 5 } & Average value, MPa & $\lg 0.5$ (max & $\lg 0.4$ (max & $\lg 0.3$ б max \\
\hline B95 & 513.5 & 2.4095 & 2.3125 & 2.1876 \\
\hline 1163 & 416.0 & 2.3180 & 2.2211 & 2.0962 \\
\hline
\end{tabular}




\section{Results and discussion}

The fatigue tests were arranged in according to the seven cyclic loading plans (Table 3). For the pulsating regular loading the follow timing scheme were taken in to plot the S-N curve the range of Logarithm of loading stresses are decided on 0.56max ( 5 specimens), $0.46 \max$ ( 5 specimens) and $0.36 \max$ (5 specimens) for each alloy sample.

Also, the same values were accepted for other positions, so every Item numbered in Table 3 includes 15 specimens.

Table 3

Experiment loading plan

\begin{tabular}{|c|c|c|}
\hline $\begin{array}{l}\text { Item number of } \\
\text { the cyclic } \\
\text { loading plan }\end{array}$ & Loading Cyclograms & Note \\
\hline It. 1 & & $\begin{array}{l}\text { Cyclic regular tensile loads timing for. } S-N \\
\text { Curve plotting. } \\
\text { The stress ranges are } 0.5 ; 0.4 \text { and } 0.3 \text { of the } \\
\text { ultimate cyclic static load } \sigma_{\max }\end{array}$ \\
\hline It. 2 & & $\begin{array}{l}\text { Single tensile } 0.8 \sigma_{\max } \text { load-peak ahead the } \\
\text { regular cyclic loading }\end{array}$ \\
\hline It. 3 & & $\begin{array}{l}\text { Single tensile } 0.8 \sigma_{\max } \text { load-peak ahead the } \\
\text { every } 1000 \text { regular loading cycles }\end{array}$ \\
\hline It.4 & & $\begin{array}{l}\text { Single compression } 0.8 \sigma_{\max } \text { load-peak } \\
\text { ahead the regular cyclic loading }\end{array}$ \\
\hline It. 5 & & $\begin{array}{l}\text { Single compression } 0.8 \sigma_{\max } \text { load-peak } \\
\text { ahead every } 1000 \text { regular loading cycles }\end{array}$ \\
\hline It. 6 & & $\begin{array}{l}\text { Single symmetric } \pm 0.8 \sigma_{\max } \text { load- peak } \\
\text { ahead the regular cyclic loading }\end{array}$ \\
\hline It.7 & & $\begin{array}{l}\text { Single symmetric } \pm 0.8 \sigma_{\max } \text { load-peak ahead } \\
\text { the every } 1000 \text { regular loading cycles }\end{array}$ \\
\hline
\end{tabular}

Tests for Item 1 of the load cyclogram (Table 3 ) were carried out at three load levels: $0.5 \sigma_{\text {nax }}$; $0.4 \sigma_{\max }$ and $0.3 \sigma_{\max }$ where $\sigma_{\max }$ ultimate tension static load (see Table 2).

The obtained fatigue durability values for the three loading levels are summarized in Table 4 . We plotted the fatigue curve in logarithmic double coordinates: $\lg \sigma-\lg N$ [4], where $\sigma-$ the current stress, $N$ - the fatigue endurance (cycles to failure) under $\sigma$ load.

Table 4 presents the main statistical characteristics of fatigue life under regular loading at three levels of specified stresses: logarithm of loading cycles to failure $\lg N$, standard deviation of the $\operatorname{logarithm} S_{\lg N}$ cycles to failure and coefficient of variation of fatigue life $V_{\mathrm{lg} N}$, \% The sample size for each position is five specimens.

Table 4 shows the main statistical fatigue characteristics versus of the fatigue life $\lg N$. 
Table 4

Parameters of the statistical characteristics of fatigue life $\lg N$ (Item 1 of loading, Table 3 )

\begin{tabular}{|c|c|c|c|c|c|}
\hline \multirow{2}{*}{ Alloy } & \multirow{2}{*}{\multicolumn{2}{|c|}{$\begin{array}{c}\text { Logarithm } S \text { of } \\
\text { applied load, Mpa }\end{array}$}} & \multicolumn{3}{|c|}{ Fatigue characteristics } \\
\hline & & & $\lg N$ & $S_{\mathrm{lg} N}$ & $V_{\operatorname{lgN}} \%$ \\
\hline \multirow{3}{*}{ B95 } & $0.5 \sigma_{\max }$ & 2.40 & 4.1351 & 0.0541 & 1.30 \\
\hline & $0.4 \sigma_{\max }$ & 2.31 & 4.4427 & 0.0656 & 1.47 \\
\hline & $0.3 \sigma_{\max }$ & 2.18 & 4.9608 & 0.0618 & 1.24 \\
\hline \multirow{3}{*}{1163} & $0.5 \sigma_{\max }$ & 2.31 & 4.4887 & 0.0365 & 0.81 \\
\hline & $0.4 \sigma_{\max }$ & 2.22 & 4.7801 & 0.0330 & 0.68 \\
\hline & $0.3 \sigma_{\max }$ & 2.09 & 5.1681 & 0.0305 & 0.59 \\
\hline
\end{tabular}

We can see, that the alloy 1163 has better fatigue strength than that one of alloy B95. That do not rejected the data of certificate documentary of alloys. But the alloy B95 characteristics of scattering, such as the standard deviation of the $\lg N$ and the coefficient of variation of the $\lg N$ way more than ones of alloy 1163. That may be explained as alloy B95 is developed for static loading better, than fatigue one (see Table 1 and [6]).

So we'll compare this two different alloys to it sensitivity to single-shot loads. Now let's consider the loading with Single tensile 0.86 max shock (peak) load ahead the regular cyclic loading - Item 2 of Table 3. The main fatigue test results are presented in Table 5

Table 5

The parameters of the $S$ - $N$ fatigue curve after the single peak cycle load $S_{s h}=0.8 \sigma_{\max }$ ahead the regular cycles (Item 2 , Table3)

\begin{tabular}{|c|c|c|c|c|c|}
\hline \multirow[b]{2}{*}{ Alloy } & \multirow{2}{*}{\multicolumn{2}{|c|}{$\begin{array}{l}\text { Logarithm of range } \\
\text { of pulsing cycle, } \\
\text { after single shock- } \\
\text { peak load } 0.8 \sigma_{\max }\end{array}$}} & \multicolumn{3}{|c|}{ Fatigue characteristics } \\
\hline & & & $\lg N$ & $S_{\lg N}$ & $V_{\lg N} \%$ \\
\hline \multirow{3}{*}{ B95 } & $0.5 \sigma_{\max }$ & 2.4094 & 4.5470 & 0.0434 & 0.97 \\
\hline & $0.4 \sigma_{\max }$ & 2.3125 & 4.9151 & 0.0359 & 0.73 \\
\hline & $0.3 \sigma_{\max }$ & 2.1876 & 5.4466 & 0.0313 & 0.57 \\
\hline \multirow{3}{*}{1163} & $0.5 \sigma_{\max }$ & 2.3180 & 4.7947 & 0.0353 & 0.73 \\
\hline & $0.4 \sigma_{\max }$ & 2.2211 & 5.3463 & 0.1223 & 0.28 \\
\hline & $0.3 \sigma_{\max }$ & 2.0962 & No less 6.1461 & no & $0.3 P_{\max }$ \\
\hline
\end{tabular}

Initial single tension overload of specimen has "training" it, thereby increasing it fatigue life. This is especially noticeable for alloy 1163 , that was designed to work under cyclic tension loads, as against alloy B95, that was designed to work in compression conditions. Let's consider the similar situation, but the same single shock (peak) loads are applied ahead EACH 1000 regular cycles. Table 6 presents the main statistical characteristics of the fatigue life at the single peak cycle ahead each 1000 regular cycles, (Item 3, Table 3).

Table 6

The parameters of the fatigue $S$ - $N$ curve after a single tension peak cycle ahead each 1000 regular cycles

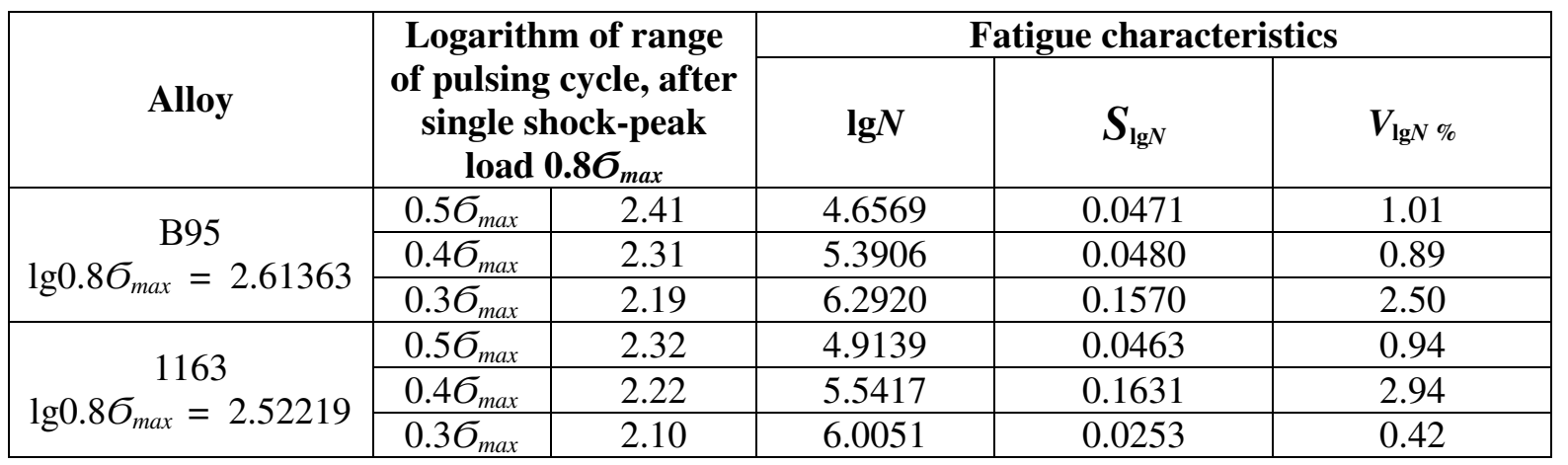


Again, it is possible to assume the effect of «training» specimens after each peak load. since block of 1000 regular cycles with preliminary peak load a head them results it to increase the fatigue life.

Similarly we may check the impact of compressive peak cycles on the fatigue life according to the similar scheme (Item.4 Table 3).

Table 7

The parameters of the fatigue $S-N$ curve after the initial single compression peak cycle ahead the regular cycles (Item 4 . Table 3)

\begin{tabular}{|c|c|c|c|c|c|}
\hline \multirow[b]{2}{*}{ Alloy } & \multirow{2}{*}{\multicolumn{2}{|c|}{$\begin{array}{l}\text { Logarithm of range } \\
\text { pulsing cycle after } \\
\text { single shock-peak } \\
\text { load } 0.8 \sigma_{\max }\end{array}$}} & \multicolumn{3}{|c|}{ Fatigue characteristics } \\
\hline & & & $\lg N$ & $S_{\lg N}$ & $V_{\operatorname{lgN}} \%$ \\
\hline \multirow{3}{*}{$\begin{array}{c}\text { B95 } \\
\lg 0.8 \sigma_{\max }=2.61363\end{array}$} & $0.5 \sigma_{\max }$ & 2.41 & 4.2057 & 0.0244 & 0.58 \\
\hline & $0.4 \sigma_{\max }$ & 2.31 & 4.3505 & 0.0694 & 1.60 \\
\hline & $0.3 \sigma_{\max }$ & 2.19 & 4.7485 & 0.0530 & 1.12 \\
\hline \multirow{3}{*}{$\begin{array}{c}1163 \\
\lg 0.8 \sigma_{\max }=2.52219\end{array}$} & $0.5 \sigma_{\max }$ & 2.32 & 4.7021 & 0.0220 & 0.47 \\
\hline & $0.4 \sigma_{\max }$ & 2.22 & 5.0956 & 0.2870 & 5.63 \\
\hline & $0.3 \sigma_{\max }$ & 2.10 & 5.3631 & 0.0509 & 0.95 \\
\hline
\end{tabular}

Examine the data it can be observed that the fatigue life of alloy 1163 after single compression peak load was reduced compared with regular cycle loading whereas in contrast the fatigue life of alloy B95. which was specially designed to work in compression conditions.

It will be interest to investigate the influence of the compression peak load ahead the EACH 1000 regular cycles. The obtained experimental data (see Table 8) show the following results.

Table 8

The parameters of the fatigue $S$ - $N$ curve after a single compression peak cycle ahead each 1000 regular cycles (Item 5. Table 3)

\begin{tabular}{|c|c|c|c|c|c|}
\hline \multirow[b]{2}{*}{ Alloy } & \multirow{2}{*}{\multicolumn{2}{|c|}{$\begin{array}{c}\text { Logarithm of range } \\
\text { pulsing cycle after } \\
\text { single shock-peak } \\
\text { load } 0.8 \sigma_{\max }\end{array}$}} & \multicolumn{3}{|c|}{ Fatigue characteristics } \\
\hline & & & $\lg N$ & $S_{\mathrm{lg} N}$ & $V_{\operatorname{lgN}} \%$ \\
\hline \multirow{3}{*}{$\begin{array}{c}\text { B95 } \\
\lg 0.8 \sigma_{\max }=2.61363\end{array}$} & $0.5 \sigma_{\max }$ & 2.41 & 4.0036 & 0.0903 & 2.26 \\
\hline & $0.4 \sigma_{\max }$ & 2.31 & 4.1951 & 0.0369 & 0.88 \\
\hline & $0.3 \sigma_{\max }$ & 2.19 & 4.5806 & 0.0318 & 0.69 \\
\hline \multirow{3}{*}{$\begin{array}{c}1163 \\
\lg 0.8 \sigma_{\max }=2.52219\end{array}$} & $0.5 \sigma_{\max }$ & 2.32 & 4.1280 & 0.1914 & 4.64 \\
\hline & $0.4 \sigma_{\max }$ & 2.22 & 4.6679 & 0.0990 & 2.12 \\
\hline & $0.3 \sigma_{\max }$ & 2.10 & 4.8849 & 0.2410 & 4.93 \\
\hline
\end{tabular}

This time out fatigue life for every sample of specimens are reduced compare to regular cyclic loading. So it is possible to accept that the repeated compressive shock (single peak) loads are most dangerous that the tension ones. Opposite. the rare tension peak loads are "fatigue training ones" for specimens that leads to bring up of its fatigue life's. It is worthy to note that compression shock loads are applied to designs and its component as impulse loads during operational work more often then tension [7].

Now it is interested to investigate the special case of applying the symmetrical single shock load tension/compressive as $\pm 0.8 \sigma_{\max }$ As before let's consider the case to impose the single symmetrical peak load before the regular cycle loading. The following data have been received (see Table 9).

As might be expected from the two opposite (single tension-compression) pulsating cycle loading compensate its effect to fatigue life of regular cycle loaded specimens. But it is known that the symmetrical cycle are the most deteriorate effect to specimens tested in fatigue but this applies to the case of total regular symmetrical cyclic loading, i.e. every cycle is symmetrical [10].

The closest approach to it is the loading of Item 7 (Table 3) then such single symmetrical cycle is applied to ahead the every 1000 regular cycles. Let study the obtained data in Table 10 
The Parameters of the fatigue $S-N$ curve when a single symmetric peak cycle is applied

Table 9 ahead the regular loading (Item 6. Table 3)

\begin{tabular}{|c|c|c|c|c|c|}
\hline \multirow{2}{*}{ Alloy } & \multirow{2}{*}{\multicolumn{2}{|c|}{$\begin{array}{c}\text { Logarithm of symmetric } \\
\text { cycle amplitude }\end{array}$}} & \multicolumn{3}{|c|}{ Fatigue characteristics } \\
\hline & & & $\lg N$ & $S_{\mathrm{lg} N}$ & $V_{\lg N} \%$ \\
\hline \multirow{3}{*}{$\begin{array}{l}\text { B95 } \\
\pm \lg 0.8 \sigma_{\max }= \pm 2.61363\end{array}$} & $0.5 \sigma_{\max }$ & 2.41 & 4.0911 & 0.0721 & 1.76 \\
\hline & $0.4 \sigma_{\max }$ & 2.31 & 4.3378 & 0.0645 & 1.49 \\
\hline & $0.3 \sigma_{\max }$ & 2.19 & 4.7232 & 0.0787 & 1.67 \\
\hline \multirow{3}{*}{$\begin{array}{l}1163 \\
\pm \lg 0.8 \sigma_{\max }= \pm 2.52219\end{array}$} & $0.5 \sigma_{\max }$ & 2.32 & 4.6688 & 0.2390 & 5.12 \\
\hline & $0.4 \sigma_{\max }$ & 2.22 & 4.8386 & 0.1360 & 2.81 \\
\hline & $0.3 \sigma_{\max }$ & 2.10 & 5.2004 & 0.2380 & 4.58 \\
\hline
\end{tabular}

Table 10

The Parameters of the fatigue $S-N$ curve when a single symmetric peak cycle is applied each 1000 regular cycles (Item 7. Table 3)

\begin{tabular}{|c|c|c|c|c|c|}
\hline \multirow{2}{*}{ Alloy } & \multirow{2}{*}{\multicolumn{2}{|c|}{$\begin{array}{l}\text { Logarithm of symmetric } \\
\text { cycle amplitude }\end{array}$}} & \multicolumn{3}{|c|}{ Fatigue characteristics } \\
\hline & & & $\lg N$ & $S_{\lg N}$ & $V_{\lg N} \%$ \\
\hline \multirow{3}{*}{$\begin{array}{l}\text { B95 } \\
\pm \lg 0.8 \sigma_{\max }= \pm 2.61363\end{array}$} & $0.5 \sigma_{\max }$ & 2.40 & 3.9816 & 0.0250 & 0.62 \\
\hline & $0.4 \sigma_{\max }$ & 2.31 & 4.0669 & 0.0741 & 1.82 \\
\hline & $0.3 \sigma_{\max }$ & 2.18 & 4.4073 & 0.0305 & 0.69 \\
\hline \multirow{3}{*}{$\begin{array}{l}1163 \\
\pm \lg 0.8 \sigma_{\max }= \pm 2.52219\end{array}$} & $0.5 \sigma_{\max }$ & 2.31 & 4.3887 & 0.2986 & 6.80 \\
\hline & $0.4 \sigma_{\max }$ & 2.22 & 4.6939 & 0.1775 & 3.78 \\
\hline & $0.3 \sigma_{\max }$ & 2.09 & 4.9564 & 0.2770 & 5.58 \\
\hline
\end{tabular}

As it may supposed the cases of shock (peak) symmetric loads greatly reduce fatigue life [11]. So we can draw a conclusion that as single compression and symmetrical loads applied ahead the regular cyclic loads have the most damaging effect to fatigue live of specimens. It is worth pointing out that the compression single peak loads simulate the impact (impulse) influence to the design and its structure elements in working (operational) condition [12].

\section{Conclusions}

The wide experiment was conducted to investigate the effect of single shock (peak) loads ahead the regular cyclic loading and ahead the each block of 1000 regular cycles to fatigue life of different alloy (B95 and 1163) specimens. The alloy B95 has been designed to offset the compression loads whereas in contrast the alloy 1163 was designed to work in tension condition. The 200 specimens of every alloy have been tested under 7 profile of loading.

It has been shown that the most damaging influence to test specimens are single compression and symmetrical peak loads ahead regular and ahead the every block of the 1000 regular cycles. At the same time the tension single peak load especial the initial single shot load "train" the material of specimens alloy to increase its fatigue endurance. This effect is more typical to specimens of alloy 1163. In opposite this alloy is very sensitive to compression single overload that led to reduce the fatigue life. It is worth pointing out that the compression single peak loads simulate the impact (impulse) influence to the design and its structure elements in working (operational) condition.

The case of single symmetrical peak load ahead the regular cycle loading as well as ahead the block of 1000 regular cycles is dangerous for both alloys. It is the more harmful condition to fatigue strength. but in fairness it must be said that this case of loading is not specific for working condition. The most often occurs the impact (tension or compression shock) under different circumstances. It is need to underwrite that in this research the peak load be equal to $80 \%$ as of ultimate static load strength.

Result of this research is the conclusion of the need to compose the design with structural significant elements that do not run in contact with shock peak loads or if is to happen anyway to realize the principle of fail-safe concept or structural health monitoring. 


\section{Acknowledgements}

This work has been supported by the European Regional Development Fund within 1.1.1. Measure 1.1.1.2 "Aid to Post-Doctoral Research" of the Specific Aid Objective "To increase the research and innovative capacity of scientific institutions of Latvia and the ability to attract external financing, investing in human resources and infrastructure" of the Operational Programmed "Growth and Employment" (No. 1.1.1.2/VIAA/1/16/104 Structural Health Monitoring system for Inflight Monitoring (FLY SAFE System).
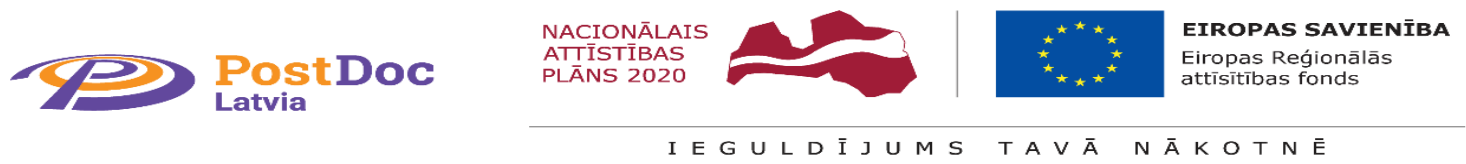

\section{References}

[1] Topper T.H., Sandor B.I. Effects of mean stress and prestrain on fatique-damage summation. Effect of environment on complex load history on fatique life. ASTM STP 462. American Socity of Testing ang Materials, 1970, pp. 93-104.

[2] Sander M., Richard H.A. Fatigue crack growth under variable amplitude loading. Experimental investigations, part I, "Institute of Applied Mechanics (FAM), University of Paderborn, Pohlweg, D-33098, Paderborn, Germany, 2005, pp. 47-49.

[3] Zhang J., Trogh S., De Waele W., Hertelé S. Fatigue Crack Propagation in HSLA Steel Specimens Subjected to Unordered and Ordered Load Spectra. In: Wahab M. (eds) Proceedings of the 13th International Conference on Damage Assessment of Structures. 2020. Lecture Notes in Mechanical Engineering. Springer, Singapore. [online][11.02.2020] Available at: https://doi.org/10.1007/978-981-13-8331-1_56

[4] Turko V. Principle of Local Zones applied to fatigue prone large-scale design, Lambert Academic Publishing. Saarbruken. Germany. 2015. 149 p.

[5] Pollard J. H. A Handbook of Numerical and Statistical Techniques. Cambridge University Press. 1977. $344 \mathrm{p}$.

[6] Urbahs A., Banovs M., Turko V., Urbaha M., Nedelko D., Lebedevs, I. Research into the features of service damage in the composite material of helicopter rotor blades. Transport Means Proceedings of the International Conference, 2019-October, 2019, pp. 466-469.

[7] Pollard J. H. A Handbook of Numerical and Statistical Techniques. Cambridge University Press. 1977. $344 \mathrm{p}$.

[8] Спецметалл (Special metal). http://nfmetall.ru/articles/32.html (In Russian).

[9] Urbahs A., Carjova K., Fescuks J. Analysis of the results of acoustic emission diagnostics of a structure during helicopter fatigue tests. Aviation. Vol.21 (2). 2017. pp. 64-69. [online][11.02.2020] Available at: https://www.tandfonline.com/doi/abs/10.3846/16487788.2017.1335231

[10] Handbook of Fatigue Testing, American Society for Testing and Materials ASTM 566, Printed in Baltimore Md, October 1974, $97 \mathrm{p}$.

[11] Prostaks, J., Urbaha, M. Evaluating accuracy of fault localization when monitoring condition of large structures by acoustic method. Engineering for Rural Development, Jelgava, 22.-24.05.2019, pp. 1280-1286.

[12] Nedelko D., Urbahs A., Turko V., Urbaha M., Carjova K., Nagaraj P. Assessment of the limits of signs of health and usage monitoring system for helicopter transmission. Procedia Computer Science, [online][11.02.2020] Available at: https://www.sciencedirect.com/science/article/pii/S1877050919301383 